\title{
Medication Practice of Patients with Dermatophytosis
}

\author{
Yogesh Poudyal, ${ }^{1}$ Shambhu Dutta Joshi² \\ 'Department of Dermatology and Venereology, Universal College of Medical Sciences, Bhairahawa, Nepal, ${ }^{2}$ Department of \\ Dermatology and Venereology, Dr. Iwamura Memorial Hospital and Research Center, Bhaktapur, Nepal.
}

\section{ABSTRACT}

Introduction: Dermatophytosis is one of the commonest dermatoses observed in Dermatology OPD. It is caused by Fungus Dermatophyte. Its pattern and prevalence varies from region to region. As self medication practice is very common, we aim to find the prevalence of various clinical pattern of dermatophytosis and to find out the medication commonly used by the patients for this condition.

Methods: This was cross sectional observational study. The case collection was done from outpatient department of Dermatology and Venereology of a Teaching Hospital from 15 ${ }^{\text {th }}$ March, 2013 to 14 March, 2014. Demographic, Clinical and other relevant details were recorded in Proforma after history and examination.

Results: The total number of cases were 594. Crural area was the most commonly involved. Tinea corporis was most common dermatophytosis followed by Tinea incognito. Risk of recurrence was highest in buttocks [odds ratio-2.404 $(1.510,3.827)$ and crural area [odds ratio- $2.298(1.637,3.266)$. Topical steroid and topical steroid with antifungal was used by $225(30.1 \%)$ and $226(30.2 \%)$ respectively. Patients who consulted dermatologist were more likely to use antifungal, odds ratio$12.060(4.907,29.643)$.

Conclusions: Tinea corporis was the commonest dermatophytosis. Due to practice of topical steroid misuse T. incognito was second common. It is essential to educate the general public, pharmacist and paramedics regarding the proper use of topical steroid.

Keywords: dermatophytosis; steroid; tinea.

\section{INTRODUCTION}

Superficial skin infection caused by dermatophyte is called dermatophytosis. It is estimated that $10-15 \%$ of the population will be infected by dermatophyte at some point in their lives. ${ }^{1}$ They have substantial clinical consequences producing chronic difficult to treat cutaneous lesion. They are contagious and have aesthetic problems. ${ }^{2}$

The prevalence of dermatophytosis in Nepal was $11.4 \%$ making it the most common dermatosis. ${ }^{3}$ The distribution of dermatophyte fungi varies from region and over time, being influenced by several factors like climatic variation, socioeconomic factors, life style and the presence of pets and age. ${ }^{4}$ It is seen in our practice that patients are using various drugs especially steroid without consultation.

It is important to understand various aspects of this disease and practice among patients regarding the

Correspondence: Dr. Yogesh Poudyal, Department of Dermatology and Venereology, Universal College of Medical Sciences- Teaching Hospital, Ranigaon, Bhairahawa, Nepal. Email: neverland791@yahoo.com. 
use of drugs and other behaviour, for effective public health measure in preventing spread and transmission of disease.

\section{METHODS}

This was cross sectional observational study. It was conducted in Dermatology and Venereology OPD of Universal College of Medical Sciences- Teaching Hospital (UCMS-TH), Bhairahawa from $15^{\text {th }}$ March 2013 to $14^{\text {th }}$ March 2014, after obtaining the permission from ethical, research and academic committee, UCMS.

All the cases of dermatophytosis presenting in dermatology OPD during this period was included. Those patients who refused to give consent and those who cannot recall their drug history properly were excluded. After history and examination the epidemiological, clinical data and other relevant details were recorded in proforma. The dermatophytosis was diagnosed by single observer clinically, in doubt $\mathrm{KOH}$ mount was taken.

Considering $11.4 \%$ prevalence of dermatophytosis; the $z$ value 1.96 for $95 \%$ confidence interval; precision $2.6 \%$, the sample size was calculated to be 573.98 , we took 594 cases. The consecutive sampling technique was used. The data was analysed using SPSS version 20. Apart from descriptive statistics measure, chi square test and odds ratio was used. The P-value was determined to be 0.05 . Dermatophytosis was grouped into 8 categories: T. corporis, T. incognito, T.cruris, T. captis, T. faciei, T. unguium, T. manuum and T. pedis.

\section{RESULTS}

The total number of cases were 594. Among them 185 $(31.1 \%)$ were female and 409 (68.9\%) were male. The mean age was $28.25 \pm 14.35$.

Seasonal variation was noted in 134 (22.6\%) cases. Recurrence of disease and positive family history was seen in $236(39.7 \%)$ and $220(37 \%)$ of cases respectively.

The most common type of dermatophytosis was $\mathrm{T}$. corporis followed by $T$. incognito (Table 1). Average number of lesion was four with average duration of disease was three months.

The distribution of dermatophytosis according to age group showed that largest number 275 was seen in age group 16-30 years, for the age group less than 15 years, 31-45 years and more than 45 years there were 97,152 and 70 cases respectively.

\begin{tabular}{|lc|}
\hline \multicolumn{2}{|l|}{ Table 1. The frequency ${ }^{*}$ of dermatophytosis. } \\
\hline Dermatophytosis & $\mathrm{n}(\%)$ \\
T. corporis & $228(31.2 \%)$ \\
T. incognito & $221(30.2 \%)$ \\
T. cruris & $149(20.4 \%)$ \\
T. capitis & $19(2.6 \%)$ \\
T. faciei & $53(7.2 \%)$ \\
T. unguium & $24(3.3 \%)$ \\
T. manuum & $10(1.4 \%)$ \\
T. pedis & $27(3.5 \%)$ \\
Total & \\
\hline
\end{tabular}

* more than one type of dermatophytosis was noted in some individuals

\begin{tabular}{|ll|}
\hline Table 2. Drugs used by patients. \\
\hline Druags & $\mathbf{n}(\%) *$ \\
Topical steroid and anti fungal & $226(30.2 \%)$ \\
Topical steroid & $225(30.1 \%)$ \\
Oral antifungal & $116(15.5 \%)$ \\
None & $78(10.4 \%)$ \\
Topical antifungal only & $49(6.6 \%)$ \\
Oral and topical anti fungals & $25(3.3 \%)$ \\
Other drugs & $29(3.9 \%)$ \\
Total & $748(100 \%)$ \\
\hline
\end{tabular}

* some patients used more than one category of drugs.

\begin{tabular}{|lccc|}
\hline \multicolumn{4}{|l|}{ Table 3. Relationship between patient's use of drugs and consultation with dermatologist. } \\
\hline Use of medication & frequency & OR & P-value \\
Topical steroid and antifungal & $34.7 \%$ & $0.838(0.550,1.276)$ & 0.237 \\
Topical steroid only & $36.4 \%$ & $0.926(0.610,1.407)$ & 0.751 \\
Oral antifungal & $15.3 \%$ & $12.060(4.907 .29 .643)$ & 0.000 \\
\hline
\end{tabular}




\begin{tabular}{|lc|}
\hline \multicolumn{2}{|c|}{ Table 4. Bathing habit and the use of soap. } \\
\hline $\begin{array}{l}\text { Characteristics } \\
\text { Use of soap } \\
\text { Daily }\end{array}$ \\
Irregularly & $254(42.8 \%)$ \\
Never & $171(28.8 \%)$ \\
Total & $169(28.4 \%)$ \\
Bathing Habit & $594(100 \%)$ \\
Daily & $465(78.3 \%)$ \\
Irregularly & $129(21.7 \%)$ \\
Total & $594(100 \%)$ \\
\hline
\end{tabular}

Table 5. Risk of recurrence at various body site.

\begin{tabular}{|lccc|}
\hline Body site & recurrence & OR & P-value \\
Crural area & $65.3 \%$ & $2.298(1.637,3.266)$ & 0.000 \\
Scalp & $0.8 \%$ & $0.183(0.042,0.802)$ & 0.013 \\
Trunk & $13.6 \%$ & $0.903(0.562,1.449)$ & 0.720 \\
Buttocks & $21.2 \%$ & $2.404(1.510,3.827)$ & \\
O.000 & & & \\
Nail & $0.8 \%$ & $0.144(0.033,0.624)$ & 0.003 \\
Palm & $2.5 \%$ & $0.309(0.644,8.270)$ & 0.206 \\
Sole & $3.0 \%$ & $0.545(0.226,1.318)$ & 0.220 \\
Lower & $26.3 \%$ & $1.279(0.872,1.877)$ & 0.123 \\
abdomen & & & \\
Face & $12.3 \%$ & $0.644(0.401,1.033)$ & 0.083 \\
\hline
\end{tabular}

The site specific distribution of the disease showed that the commonest site was crural area 315 (39.6\%) followed by lower abdomen and face 140 (17.6\%) and $93(11.7 \%)$ respectively, other involved sites were buttocks, upper trunk, sole, nail, scalp,palm. More than one site were involved in some individual. Secondary changes due to steroid use like striae, atrophy, telengiectasia and hypopigmentation was seen in $7(1.2 \%), 23(3.9 \%), 12(2.0 \%)$ and $38(6.4 \%)$ respectively.

The data regarding the patient's use of various drugs for the treatment of dermatophytosis showed maximum number of patients were using steroid cream (Table 2). Other drugs includes herbal or ayurvedic preparation, homeopathic preparation, antibiotic and oral steroid. The patient's practice in using various drugs was analysed. It was found that the practice of antifungal use was more likely in patients who took consultation from the dermatologist and there was less likelihood of patient using steroid if patient consulted the dermatologist (Table 3).

The data regarding the patient's hygiene in terms of regular bath and patient's attitude regarding the use of soap was taken. It was found that $28.5 \%$ never used soap because of this disease, few of them used local scrubbing preparation called pinna. All of them have concept that use of soap will exacerbate the disease (Table 4).

Risk of recurrence of disease at various body site was analysed. It was found that risk of recurrence was highest at crural area and buttocks and was statistically significant (Table 5).

\section{DISCUSSION}

The commonest type of dermatophytosis was Tinea corporis, maximum number of patients had misused topical steroid. Crural area was the most common site for dermatophytosis and also the commonest site for recurrence.

There are variations in prevalence of type of dermatophytosis. Study by Dichiacchio ${ }^{4}$ showed T. unguium to be the commonest, but like our study the study by Asticcioti ${ }^{5}$ showed $\mathrm{T}$. corporis to be the commonest. Tinea pedis was most common in study done in Peru. ${ }^{6}$ This shows that prevalence varies according to region.

The commonest site of dermatophytosis in our study was crural area. This is in accordance with some previous studies. ${ }^{7-9}$ Crural area is more moist than other body parts, and since moisture encourages growth of fungus, the frequent recurrence at this part may be explained.

It was seen that $30.1 \%$ were using topical steroid and $30.2 \%$ were using steroid and antifungal combination preparation. There was statistically significant result showing patient were misusing steroid for the treatment. It clearly showed that patient who have not consulted dermatologist are likely to use steroid. Steroid only reduces inflammation and that is seen clinically as decreased erythema and pruritus and patient feels symptomatically better, and patients often take this as a cure. As soon as patient stop application, the erythema and pruritus recurs. Then the patients keeps on reusing it. This in long run gives various skin related complications like striae, telengiectasia, atrophy and due to chronicity of disease there is increased possibility of transmission. No published literature regarding dermatophytosis and steroid misuse was noted, but the prevalence of self medication pattern was high in different parts of world. ${ }^{10,11}$ For dermatological condition the prevalence of self medication ranged from 6 to $45 \% .{ }^{12}$ One study from Iraq showed about $7.9 \%$ had steroid abuse, for general dermatological condition. ${ }^{13}$ But our study showed as much as $71.1 \%$ combining 
both only steroid and in form of steroid and antifungal combination both. This is significantly high. This large number of steroid misuse can be due to easy availability of drug with out prescription; lack of awareness among health personnel especially pharmacist about the potential side effect of steroid and difficulty in access to dermatologist's service. It is important to educate the public and the health care providers like pharmacist and other paramedical staffs who often dispense the drugs in this region, about drawbacks of steroid use in dermatophytosis.

The most prevalent age group was $16-30$ years of age, this is similar to the studies in past. 8,14 This may be due to fact that this is most active group, so the rate of transmission may be high in this group.

It was found that $28.7 \%$ had stopped using soap, due to the concept that soap may exacerbate dermatophytosis. Regular use of soap was even recommended as the low cost and effective treatment option for dermatophytosis. ${ }^{15}$ So it was seen that patients should also get proper information regarding the use of soap.

Dermatophytosis was found more in male than in female. This is consistent with the result done in past. $6,7,14,16$ It is said that sex may influence the susceptibility to particular forms of infection. Progesterone has been shown to prevent dermatophyte multiplication in vitro. Males may be more vulnerable to infection due to the higher exposure in the army, school and sporting activities and due to type of shoes and shocks used. ${ }^{17}$

Since no written record of the drug used were available, there was high probability of recall bias in our study.

\section{CONCLUSIONS}

Tinea corporis is the most common dermatophytosis. Due to steroid misuse, Tinea incognito is the second common. It is important to educate public and paramedics and pharmacist about the drawbacks of improper use of steroid. One of the cause of high prevalence of dermatophytosis in this region may be implicated to the steroid misuse.

\section{REFERENCES}

1. Pires CAA, Cruz NFS, Lobato AM, Sousa PO, Carneiro FRO,Mendes AMD. Clinical, epidemiological and therapeutic profile dermatophytosis. An Bras Dermatol. 2014;89(2):259-264.

2. Wille MP, Arantes TD, Monteiroda Silva JL. Epidemiology of dermatomycosis in population in the outskirts of Araraquara. Rev Bras Clin Med. 2009;7:295-98

3. Walker SL, Shah M, Hubbard VG, Pradhan HM, Ghimire M. Skin disease is common in rural Nepal: result of point prevalence study. BJD. 2008;158:334-38

4. Dichiacchio N, Madeira CL, Humaire CR, Silva CS, Fernandes LHG, Reis ALD. Superficial mycosis at the Hospital do Servidor Publico municipal de sao Paulo between 2005 and 2011. An Bras Dermatol. 2014;89:67-71.

5. Asticcioli S, Silverio AD, Sacco L, Fusi I, Vincenti L, Ramero E. Dermatophyte infection in patients attending tertiary care hospital in Italy. New Microbiologica. 2008;31:543-48.

6. Flores JM, Castillo VB, Franco FC, Huata AB. Superficial fungal infection: clinical and epidemiological study in adolescent from marginal districts of Lima and Callao, Peru. J infect Dev Ctries. 2009;3(4):313-17.

7. Mahmoudabadi AZ. A study of Dermatophytosis in south west of Iran. Mycopathologia. 2005;160:21-24.

8. Aghamirian MR, Ghiasian SA. Dermatophytosis in outpatients attending the dermatology center of Avicenna Hospital in Qiazvin, Iran. Mycoses. 2007;51:155-60.

9. Aboueisha AM, El-Mahallawy H. Public health significance of dermatophytes in Ismailia and port said province, Egypt. Med Mycol J. 2013;54:123-29.
10. Biswas A, Sen S, Pal A, Das J, Das S, Tripathi SK. Self medicational trend among the urban elderly- a cross sectional observational study. Asian Journal of medical sciences. 2015;6(5):66-68.

11. Awad AI, Eltayeb IB,Capps PA. Self medication practices in Khartoum state, sudan. Eur J Clin Pharmacol. 2006;62:317-24.

12. Correa-Fissmer M, Mendonca MG, Martins AH, Galate D. Prevalence of self medication for skin diseases:a systematic review. An Bras Dermatol. 2014;89(4):625-30.

13. Al-Dhalimi MA, Alijawahiry N. Misuse of topical corticosteroids: a clinical study in an Iraqi hospital. East mediterr health J. 2006;12(6):847-52.

14. Mathur M, kedia SK, Ghimire RB. 'Epizoonosis of dermatophytosis' a clinic-mycological study of dermatophytic infection in cemtral Nepal. KUMJ. 2012;10(37): 30-33.

15. Dinkela A, Ferie J, Mibata $M$, Schmid-Grendelmeier $M$, Hartz C. Efficacy of triclosan soap against superficial dermatomycosis: a double blind clinical trial in 224 primary school children in kilombero district, Morogoro region Tanzania. Int J Dermatol. 2007;46(suppl 2):23-28.

16. Metintas S, Kiraz N, Arslantas D, Akgun Y, Kalyoncu C, et al. Frequency and risk factors of dermatophytosis in students living in rural areas in Eskisehir, Turkey. Mycopathologia. 2004;157:379-82

17. Poudyal $Y$, Rajbhandari SL. Pattern of skin disease in patient visiting universal college of medical sciences-Teaching Hospital (UCMS-TH) from the three districts of terai region in Nepal. JUCMS. 2014;2(3):3-8. 